\title{
Change in forced vital capacity and associated subsequent outcomes in patients with newly diagnosed idiopathic pulmonary fibrosis
}

William M. Reichmann ${ }^{1}$, Yanni F. Yu ${ }^{2}$, Dendy Macaulay ${ }^{3 *}$, Eric Q. Wu ${ }^{1}$ and Steven D. Nathan ${ }^{4}$

\begin{abstract}
Background: Idiopathic pulmonary fibrosis (IPF) is a rare and serious disease characterized by progressive lung-function loss. Limited evidence has been published on the impact of lung-function loss on subsequent patient outcomes. This study examined change in forced vital capacity (FVC) across IPF patients in the 6 months after diagnosis and its association with clinical and healthcare resource utilization (HRU) outcomes in a real-world setting in the U.S.

Methods: A retrospective chart review was conducted of patients diagnosed with IPF by U.S. pulmonologists. Patient eligibility criteria included: 1) 40 years or older with a confirmed date of first IPF diagnosis with high-resolution computed tomography and/or lung biopsy between 01/2011 and 06/2013; 2) FVC results recorded at first diagnosis ( \pm 1 month) and at 6 months ( \pm 3 months) following diagnosis. Based on relative change in FVC percent predicted (FVC\%), patients were categorized as stable (decline $<5 \%$ ), marginal decline (decline $\geq 5 \%$ and $<10 \%$ ), or significant decline (decline $\geq 10 \%$ ). Physician-reported clinical and HRU outcomes were assessed from $\sim 6$ months post-diagnosis until the last contact date with the physician and compared between FVC\% change groups. Multivariable Cox proportional-hazards models were constructed to assess risk of mortality, suspected acute exacerbation (AEx), and hospitalization post-FVC\% change. Generalized estimating equations were used to account for multiple patients contributed by individual physicians.
\end{abstract}

Results: The sample included 490 IPF patients contributed by 168 pulmonologists. The mean (SD) age was 61 (11) years, $68 \%$ were male, and the mean (SD) baseline FVC\% was $60 \%$ (26\%). 250 (51\%) patients were categorized as stable, 98 (20 \%) as marginal decline, and 142 (29\%) as significant decline. The mean (SD) observation time was 583 (287) days. In both unadjusted analysis and multivariable models, significantly worse clinical outcomes and increased HRU were observed with greater lung-function decline.

Conclusions: These findings suggest that nearly half of IPF patients experienced decline in FVC\% within $\sim 6$ months following IPF diagnosis. Greater FVC\% decline was associated with an increased risk of further IPF progression, suspected AEx, mortality, and higher rate of HRU. Management options that slow FVC decline may help improve future health outcomes in IPF.

Keywords: Idiopathic pulmonary fibrosis, Forced vital capacity, Healthcare resource utilization, Clinical outcomes

\footnotetext{
* Correspondence: Dendy.Macaulay@analysisgroup.com

${ }^{3}$ Analysis Group, Inc., New York, NY, USA

Full list of author information is available at the end of the article
} 


\section{Background}

Idiopathic pulmonary fibrosis (IPF) is a rare, chronic, and serious pulmonary disease of unknown etiology characterized by the progressive loss of lung function. The prevalence of IPF in the U.S. is estimated to be 14 to 43 per 100,000 person-years and increases with age [1]. More recent incidence and prevalence estimates among the elderly U.S. population are 91 and 495 cases per 100,000 person-years [2]. Following diagnosis, the prognosis is generally poor, with a median survival time of approximately 3-5 years [3, 4]. Patients with IPF may remain stable, progress steadily over time, progress rapidly, or experience episodes of acute deterioration, some of which can be acute exacerbations (AEx) [5]. Until recently, treatment options for IPF patients in the U.S. had been limited to oxygen therapy, pulmonary rehabilitation, and, in select cases, lung transplantation [5, 6]. In October 2014, the Food and Drug Administration approved two new pharmacologic agents for IPF, expanding treatment options $[7,8]$. Both drugs have been recommended for use in the 2015 update to the 2011 ATS/ERS/JRS/ALAT IPF clinical practice guidelines [9].

The variable clinical course of IPF presents a challenge to predicting disease progression and managing care of patients [3]. Given the limited treatment options and the substantial impact of the disease on patients' health outcomes $[10,11]$, increased evidence regarding the clinical progression of IPF are needed. Previous studies have shown that patients with IPF have significantly higher healthcare resource utilization (HRU) compared to matched controls $[12,13]$ as well as an increased risk of death [14]. Martinez et al. reported on the clinical course of IPF in a multicenter randomized controlled trial and observed frequent hospitalizations and rapid progression of lung disease in patients who died due to IPF [15]. Further, decline in FVC has been shown to be associated with an increased risk of progression and death [16-18]. However, studies have not examined the relationship between lung-function change and other clinical outcomes, such as AEx or HRU. The research gap arises in part due to difficulty in obtaining measures of lung function at time points throughout the course of disease in the real world. Such data could be useful for key stakeholders, especially with the recent availability of disease modulating therapies for IPF.

This study aimed to address the evidence gap through the use of chart data extracted by treating pulmonologists from a nationwide panel in the U.S. The existing literature have been constrained to either post-hoc analyses of patients from randomized controlled trials or observational studies from single centers, neither of which may be representative of the broader IPF population. The approach used in this study allowed for a study population with a sufficient sample size that would be representative of a variety of treatment settings. The objective of this study was to assess the association of lung-function change with clinical outcomes and IPFrelated HRU in patients with newly diagnosed IPF.

\section{Methods}

\section{Data source}

A retrospective chart review was conducted by pulmonologists from a nationally representative panel using an online case report form. The panel comprised over 1,000 pulmonologists working in both academic and non-academic institutions, and covered all regions in the U.S. The pulmonologist panel was demographically similar to those on the American Medical Association master list [19].

\section{Sample selection}

Pulmonologists on the panel were invited via e-mail to participate. Those who accepted the invitation completed a questionnaire to assess their eligibility. Pulmonologists were eligible to participate if they had complete access to their patients' (inpatient and outpatient) IPF-related medical records. Eligible physicians were then requested to randomly select IPF patients who met the inclusion criteria for this study. IPF patients were eligible for chart abstraction if they met the following criteria: 1) 40 years or older with a confirmed date of first IPF diagnosis with HRCT and/or lung biopsy between January 1, 2011 and June 30, 2013; and 2) the patient's pulmonary function tests measured using FVC were recorded at or around first IPF diagnosis ( \pm 1 month) and at or around 6 months ( \pm 3 months) following diagnosis.

Pulmonologists were compensated for their participation and remained anonymous to the study sponsor and vice versa. The electronic case report form and study synopsis were reviewed by the New England Institutional Review Board, which granted exemption from a full review because this non-interventional study collected retrospective, de-identified data. Patient consent forms were not required, and the chart abstraction form did not request any information that could be linked to a patient's identity, such as name, date of birth, date of death, or social security number.

\section{Study period}

Data were collected from the date of initial IPF diagnosis until last follow-up. The last follow-up date was defined as either: 1) the last contact the pulmonologist had with the patient for those who were alive as of chart abstraction; or 2) the date of death for the deceased. The study period was divided into two time periods, concurrent and subsequent. The "concurrent period" was defined as the time from initial IPF diagnosis date to the FVC measurement closest to 6 months post-IPF diagnosis. The "subsequent period" was defined as the time from 
the FVC measurement date closest to 6 months postIPF diagnosis to the last follow-up date (i.e., end of the study period) with no requirement for minimum length of follow-up. The length of the concurrent and subsequent periods therefore varied for patients.

\section{Independent variables and outcome measures}

The main independent variable of interest was relative change in $\mathrm{FVC}$ percent predicted (FVC\%) over 6 months. The stable group was defined as $<5 \%$ decrease in $\mathrm{FVC} \%$, the marginal decline group as $\geq 5 \%$ and $<10 \%$ decrease in FVC\%, and the significant decline group as $\geq 10 \%$ decrease in $\mathrm{FVC} \%$. Other lung-function measures collected included forced expiratory volume after $1 \mathrm{~min}\left(\mathrm{FEV}_{1}\right)$, $\mathrm{FEV}_{1} / \mathrm{FVC}$ ratio, and the single breath diffusing capacity for the lung for carbon monoxide $\left(\mathrm{DL}_{\mathrm{CO}}\right)$. The GAP index was also calculated at the initial IPF diagnosis based on the patient's gender, age, $\mathrm{FVC} \%$, and $\mathrm{DL}_{\mathrm{CO}}$ values [20]. In order to estimate the GAP index for all patients, missing $\mathrm{DL}_{\mathrm{CO}}$ values were imputed for 108 patients (22\%) using single imputation (see Appendix).

Clinical and IPF-related HRU outcomes were collected during the subsequent period and were based on physician report. Clinical outcomes included all-cause mortality, mortality due to IPF, mortality due to a suspected AEx, suspected AEx, and IPF progression. Suspected AEx was defined by asking participating pulmonologists if a particular outpatient visit, emergency room (ER) visit, or hospitalization was related to an IPF AEx. IPF progression was based on physician assessment. Physicians were asked if the patient had experienced one of the following since the previous visit: progressive dyspnea, increased cough, sustained decrease from baseline in absolute $\mathrm{FVC}$ and $\mathrm{DL}_{\mathrm{CO}}$, progression of fibrosis from baseline on HRCT, AEx, respiratory failure, or new need for supplemental oxygen or increase in oxygen requirements.

IPF-related HRU outcomes were collected in the outpatient, ER, and hospital settings. Outcomes in the outpatient setting included the timing and number of outpatient visits, outpatient visits that were unscheduled and/or for urgent care, and outpatient visits that were for suspected AEx. Also documented were the timing and number of visits where prednisone, azathioprine, and/or $\mathrm{N}$-acetylcysteine were prescribed and where arterial blood gas test, high-resolution computed tomography, chest $\mathrm{x}$-ray, lung biopsy, and/or pulmonary rehabilitation were conducted for IPF. Similar outcomes were documented when patients presented to the ER and hospital settings.

Information on the above clinical and HRU variables was also collected for the concurrent period to assess whether patients in different $\mathrm{FVC} \%$ change groups had different characteristics in the concurrent period.

\section{Statistical analysis}

Summary statistics for characteristics of the treating physician and their practice were calculated. Patient characteristics at the time of diagnosis were compared between patients in different $\mathrm{FVC} \%$ change groups.

The incidence rate (IR) or risk of clinical and HRU outcomes was assessed using unadjusted regression analysis with $\mathrm{FVC} \%$ change group as the only independent variable and was estimated at the per-patient-half-year level for the concurrent period and per-patient-year level for the subsequent period. Negative binomial regression was used to estimate the incidence rate ratio (IRR) and its $95 \%$ confidence interval (CI) for count variables. Logistic regression was used to estimate the odds ratio (OR) and its $95 \% \mathrm{CI}$ for binary variables except for mortality. For both models, patient-specific offset terms were used to account for varying follow-up time. For mortality, Kaplan-Meier analysis was performed to obtain the risk of death by 12 months, and an unadjusted Cox proportional hazards regression was used to estimate the hazard ratio (HR) and its $95 \%$ CI. As a sensitivity analysis, the stable and marginal decline groups were combined, and HRU outcomes were compared between this combined group and the significant decline group (See Appendix), i.e., FVC\% decline $<10 \%$ vs. FVC\% decline $\geq 10 \%$.

Additionally, multivariable Cox proportional hazards regressions were constructed to assess factors associated with risk of mortality, hospitalization, and suspected AEx. For each model, the main independent variable of interest was the $\mathrm{FVC} \%$ change group while the control variables consisted of physician's main practice setting, patient characteristics and symptoms at IPF diagnosis, smoking status, GAP index, suspected AEx in the concurrent period, and use of prednisone and azathioprine in the concurrent period. The combination therapy of prednisone and azathioprine was included per the findings of the PANTHER-IPF clinical trial, which found the triple drug combination of prednisone, azathioprine, and n-acetylcysteine to significantly increase mortality risk relative to placebo [21]. In constructing the Cox regressions, the proportional hazards assumption was tested and found to be satisfied for the FVC\% change group variables for all models. The HR and $95 \%$ CI for each risk factor were estimated.

All regression analyses used the generalized estimating equations (GEE) technique to account for correlation from the clustering of multiple patient charts contributed by the same pulmonologist. $P$-values for all pairwise comparisons of $\mathrm{FVC} \%$ change groups were adjusted for multiple comparisons using a Bonferroni correction, and $p$-values that were less than 0.05 were considered to be statistically significant. All statistical analyses were performed using SAS version 9.3. 


\section{Results}

\section{Physician characteristics}

A total of 168 pulmonologists participated in this study, of whom 69 (41.1\%) practiced in an academic setting. The practices were distributed across the Northeast (36.3\%), South (25.0\%), Midwest (20.8\%) and West (17.9\%) of the U.S. The mean (SD) number of years in practice for the pulmonologists was 15.0 (6.4), with each on average contributing data abstracted from 3 patient charts (Appendix: Table 9).

\section{Patient characteristics}

Four-hundred ninety IPF patients were included in this study, of which 250 (51.0\%) were classified as stable, 98 (20.0\%) were classified as having a marginal decline, and $142(29.0 \%)$ were classified as having a significant decline. The mean (SD) follow-up time for the entire sample was 583 (287) days with the average length of the concurrent and subsequent periods being 176 (56) and 407 (283) days, respectively. The majority of the IPF patients were male $(68.4 \%)$, and the average age was 61.1 (10.8) years. The majority of patients were of White race $(75.3 \%)$ and were enrolled in commercial/private insurance $(48.6 \%)$ or Medicare (43.7\%) (Table 1).

At the initial IPF diagnosis date, the mean (SD) FVC of the population was 2.5 (1.0) liters, and the mean (SD) FVC\% was $60.4 \%(26.1 \%)$, while the mean (SD) $\mathrm{DL}_{\mathrm{CO}}$ percent predicted was $51.3 \%$ (15.5\%). The mean GAP index was 3.3 (1.5) out of a maximum score of 8 (highest risk). The most common IPF symptoms at diagnosis were dyspnea or shortness of breath (87.6\%), cough (72.7\%), and fatigue or malaise $(47.3 \%)$. Gastroesophageal reflux disease was the most commonly reported comorbidity (31.2 \%). Generally, patient characteristics were not significantly different among the three FVC\% change groups. The significant decline group had lower $\mathrm{DL}_{\mathrm{CO}}$ and $\mathrm{FEV}_{1}$ values than the stable group ( $47.7 \%$ vs. $53.4 \%$ for $\mathrm{DL}_{\mathrm{CO}}, p=0.033 ; 1.7$ vs. 2.0 liters for $\mathrm{FEV}_{1}, p=0.021$ ) (Table 2). The significant decline group also had higher rates of dyspnea and gradual, unintended weight loss than the stable group (93.0\% vs. $83.6 \%$ for dyspnea, $p=0.030 ; 16.9 \%$ vs. $6.8 \%$ for unintended weight loss, $p=0.035$ ).

\section{Unadjusted analysis of clinical characteristics and HRU in the concurrent period}

No significant differences were observed between the FVC\% change groups in the concurrent period with regards to rate or risk of suspected AEx and HRU. The exception to this was risk of progression, which was higher for the significant and marginal decline groups compared to the stable group (Table 3 ).

\section{Unadjusted analysis of clinical outcomes in the subsequent period}

Significantly higher risk of worse clinical outcomes were observed in groups with greater $\mathrm{FVC} \%$ decline, including risk of progression (significant vs. stable, $>3$-fold higher), risk of suspected AEx (significant vs. stable, >4-fold higher; marginal vs. stable, $>2$-fold higher), all-cause mortality (significant vs. stable, $>5$-fold higher; significant vs. marginal, 1.8-fold higher; marginal vs. stable, $>2$-fold higher), mortality due to IPF (significant vs. stable, >6-fold higher; significant vs. marginal, 1.9-fold higher; marginal vs. stable, $>3$-fold higher), and mortality due to a suspected AEx (significant vs. stable, $>3$-fold higher; marginal vs. stable, $>3$-fold higher) (Table 4 ). In the stable and marginal decline groups, mortality due to a suspected AEx was similar to all-cause and IPF-related mortality, indicating that suspected AEx was likely the main driver of mortality in these groups. However, in the significant decline group, mortality due to suspected AEx was approximately half that of all-cause and IPF-related mortality, indicating that progression of IPF might be the main driver of mortality in this group.

\section{Unadjusted analysis of HRU outcomes in the subsequent period}

During the subsequent period, the overall IRs of outpatient visits, ER visits, and hospitalization were 2.39, 0.43, and 0.34 per patient-year, respectively. The corresponding overall 12-month risks of outpatient visits, ER visits, and hospitalization were $96.6 \%, 21.5 \%$ and $15.2 \%$, respectively. Significantly higher rates were observed in groups with greater FVC\% decline for the following variables: outpatient visits for a suspected AEx, unscheduled and/or urgent care outpatient visits, hospitalization for a suspected AEx, treatments and medications prescribed at outpatient visits, arterial blood gas tests used in the ER setting, number of days in the hospital, ICU stays, and tests used in the hospital setting (Table 5). Similar results were found when the marginal and stable groups were combined and compared with the significant group (Appendix: Table 10).

\section{Multivariable analysis}

Results of the Cox proportional hazards regressions showed that greater FVC\% decline was associated with a higher risk of mortality, hospitalization, and suspected AEx in the subsequent period, adjusting for demographic and clinical characteristics. In addition, suspected AEx in the concurrent period was found to be associated with higher risk of mortality $(\mathrm{HR}=2.59, p<$ $0.001)$, hospitalization $(\mathrm{HR}=1.86, p=0.030)$, and subsequent suspected $\operatorname{AEx}(\mathrm{HR}=2.98, p<0.001)$ in the subsequent period (Tables 6, 7, and 8). 
Table 1 Baseline characteristics by FVC\% change group

\begin{tabular}{|c|c|c|c|c|c|c|}
\hline & \multicolumn{6}{|c|}{ By lung-function change category (based on relative change in FVC\%) } \\
\hline & \multirow{2}{*}{$\begin{array}{l}\text { Stable }[A] \\
(N=250)\end{array}$} & \multirow{2}{*}{$\begin{array}{l}\text { Marginal }[B] \\
(N=98)\end{array}$} & \multirow{2}{*}{$\begin{array}{l}\text { Significant }[C] \\
(N=142)\end{array}$} & \multicolumn{3}{|l|}{$P$-value* } \\
\hline & & & & {$[\mathrm{C}]$ vs. $[\mathrm{A}]$} & [C] vs. [B] & {$[B]$ vs. $[A]$} \\
\hline Male, N (\%) & $167(66.8 \%)$ & 70 (71.4\%) & $98(69.0 \%)$ & 0.999 & 0.999 & 0.999 \\
\hline Age (years), mean (SD) & $60.8(10.8)$ & $62.1(9.6)$ & $60.9(11.5)$ & 0.999 & 0.999 & 0.930 \\
\hline BMI, mean (SD) & $26.7(4.9)$ & $26.5(4.4)$ & $26.3(4.6)$ & 0.999 & 0.999 & 0.999 \\
\hline \multicolumn{7}{|l|}{ Race, N (\%) ${ }^{\mathrm{b}}$} \\
\hline White & $183(73.2 \%)$ & $82(83.7 \%)$ & $104(73.2 \%)$ & 0.999 & 0.193 & 0.098 \\
\hline Black or African American & $34(13.6 \%)$ & $11(11.2 \%)$ & $24(16.9 \%)$ & 0.999 & 0.650 & 0.999 \\
\hline Hispanic, Latino, or Spanish Origin & $26(10.4 \%)$ & $5(5.1 \%)$ & $13(9.2 \%)$ & 0.999 & 0.646 & 0.295 \\
\hline Asian & 7 (2.8 \%) & $1(1.0 \%)$ & 1 (0.7 \%) & 0.479 & 0.999 & 0.952 \\
\hline Other & $2(0.8 \%)$ & $0(0.0 \%)$ & $0(0.0 \%)$ & & & \\
\hline \multicolumn{7}{|l|}{ Insurance type, N (\%) ${ }^{\mathrm{b}}$} \\
\hline Commercial/private insurance & $113(45.2 \%)$ & $45(45.9 \%)$ & $80(56.3 \%)$ & 0.193 & 0.502 & 0.999 \\
\hline Medicare & $109(43.6 \%)$ & $44(44.9 \%)$ & $61(43.0 \%)$ & 0.999 & 0.999 & 0.999 \\
\hline Medicaid & $26(10.4 \%)$ & $12(12.2 \%)$ & $17(12.0 \%)$ & 0.999 & 0.999 & 0.999 \\
\hline Military insurance (VA or active military) & $9(3.6 \%)$ & $2(2.0 \%)$ & $3(2.1 \%)$ & 0.999 & 0.999 & 0.999 \\
\hline Other & $0(0.0 \%)$ & $1(1.0 \%)$ & $0(0.0 \%)$ & - & - & - \\
\hline No insurance & $8(3.2 \%)$ & $1(1.0 \%)$ & 1 (0.7 \%) & 0.228 & 0.999 & 0.584 \\
\hline Smoking status at diagnosis, N (\%) & & & & 0.789 & 0.999 & 0.999 \\
\hline Never smoked & $98(39.2 \%)$ & $44(44.9 \%)$ & $48(33.8 \%)$ & & & \\
\hline Former smoker & $124(49.6 \%)$ & $42(42.9 \%)$ & $77(54.2 \%)$ & & & \\
\hline Current smoker & $21(8.4 \%)$ & $11(11.2 \%)$ & $16(11.3 \%)$ & & & \\
\hline Unknown/not sure & $7(2.8 \%)$ & $1(1.0 \%)$ & $1(0.7 \%)$ & & & \\
\hline \multicolumn{7}{|c|}{ Exposure to activities/ environmental agents, $\mathrm{N}(\%)^{\mathrm{b}}$} \\
\hline Asbestos & $10(4.0 \%)$ & $3(3.1 \%)$ & $11(7.7 \%)$ & 0.336 & 0.650 & 0.999 \\
\hline Farming/agriculture & $27(10.8 \%)$ & $9(9.2 \%)$ & $25(17.6 \%)$ & 0.213 & 0.131 & 0.999 \\
\hline Hairdressing & $12(4.8 \%)$ & $4(4.1 \%)$ & $4(2.8 \%)$ & 0.999 & 0.999 & 0.999 \\
\hline Metal dust & $18(7.2 \%)$ & $2(2.0 \%)$ & $10(7.0 \%)$ & 0.999 & 0.172 & 0.154 \\
\hline Stone cutting/polishing & $7(2.8 \%)$ & $0(0.0 \%)$ & $6(4.2 \%)$ & 0.999 & $<0.001^{*}$ & $<0.001^{*}$ \\
\hline Coal mining & $5(2.0 \%)$ & $1(1.0 \%)$ & $2(1.4 \%)$ & 0.999 & 0.999 & 0.999 \\
\hline Other & $3(1.2 \%)$ & $3(3.1 \%)$ & $2(1.4 \%)$ & 0.999 & 0.999 & 0.669 \\
\hline None & $182(72.8 \%)$ & 78 (79.6\%) & $92(64.8 \%)$ & 0.340 & $0.037^{*}$ & 0.598 \\
\hline Family history of pulmonary fibrosis, N (\%) & $16(6.4 \%)$ & $6(6.1 \%)$ & $5(3.5 \%)$ & 0.564 & 0.923 & 0.999 \\
\hline \multicolumn{7}{|l|}{ Measurement period (days) } \\
\hline Concurrent, mean (SD) & $172.8(55.5)$ & $174.9(53.7)$ & $181.6(56.8)$ & 0.575 & 0.999 & 0.999 \\
\hline Subsequent, mean (SD) & $438.3(283.1)$ & $423.0(280.0)$ & $340.1(275.9)$ & $0.013^{*}$ & 0.118 & 0.999 \\
\hline Total follow-up, mean (SD) & $611.1(282.7)$ & $597.9(285.8)$ & $521.7(286.6)$ & $0.036^{*}$ & 0.225 & 0.999 \\
\hline
\end{tabular}

a Lung-function change categories were defined as the relative change in FVC\% from index to approximately 6 months following IPF diagnosis. "Stable" was defined as decline $<5 \%$. "Marginal" was defined as decline $\geq 5 \%$ and $<10 \%$, while "Significant" was defined as decline $\geq 10 \%$

${ }^{b}$ Physicians were allowed to select multiple values for race, insurance type, and exposure to activities/environmental agents, so counts and percentages may not sum to the total $\mathrm{N}$ or $100 \%$

*All $p$-values were adjusted for multiple comparisons using the Bonferroni correction

\section{Discussion}

This study was a retrospective chart review of patients diagnosed with IPF designed to investigate the relationship of FVC\% change with clinical and HRU outcomes.
Overall, clinical characteristics and HRU were similar between $\mathrm{FVC} \%$ change groups at initial IPF diagnosis and in the concurrent period. However, both unadjusted analysis and multivariable analysis showed that greater 
Table 2 Clinical characteristics at initial IPF diagnosis by FVC\% change group

\begin{tabular}{|c|c|c|c|c|c|c|}
\hline & \multicolumn{6}{|c|}{ By lung-function change category (based on relative change in FVC\%) } \\
\hline & \multirow{2}{*}{$\begin{array}{l}\text { Stable }[\mathrm{A}] \\
(\mathrm{N}=250)\end{array}$} & \multirow{2}{*}{$\begin{array}{l}\text { Marginal }[\mathrm{B}] \\
(\mathrm{N}=98)\end{array}$} & \multirow{2}{*}{$\begin{array}{l}\text { Significant }[C] \\
(N=142)\end{array}$} & \multicolumn{3}{|l|}{$P$-value* } \\
\hline & & & & {$[\mathrm{C}]$ vs. $[\mathrm{A}]$} & {$[\mathrm{C}]$ vs. $[\mathrm{A}]$} & {$[\mathrm{C}]$ vs. $[\mathrm{A}]$} \\
\hline \multicolumn{7}{|l|}{ Comorbidities, $\mathrm{N}(\%)^{\mathrm{b}}$} \\
\hline Gastroesophageal reflux disease & $82(32.8 \%)$ & $26(26.5 \%)$ & $45(31.7 \%)$ & 0.999 & 0.999 & 0.999 \\
\hline Cardiac disorder & $43(17.2 \%)$ & $28(28.6 \%)$ & $34(23.9 \%)$ & 0.260 & 0.999 & 0.053 \\
\hline Metabolic disorder & $38(15.2 \%)$ & $20(20.4 \%)$ & $29(20.4 \%)$ & 0.500 & 0.999 & 0.642 \\
\hline Other vascular disorder & $32(12.8 \%)$ & $23(23.5 \%)$ & $27(19.0 \%)$ & 0.300 & 0.999 & 0.069 \\
\hline Pulmonary hypertension & $31(12.4 \%)$ & $20(20.4 \%)$ & $16(11.3 \%)$ & 0.999 & 0.095 & 0.198 \\
\hline Emphysema & $18(7.2 \%)$ & $8(8.2 \%)$ & $15(10.6 \%)$ & 0.783 & 0.999 & 0.999 \\
\hline Other pulmonary disorder & $14(5.6 \%)$ & 7 (7.1\%) & $13(9.2 \%)$ & 0.435 & 0.999 & 0.999 \\
\hline \multicolumn{7}{|l|}{ Symptoms at IPF diagnosis, N (\%) } \\
\hline Dyspnea/shortness of breath & $209(83.6 \%)$ & $88(89.8 \%)$ & $132(93.0 \%)$ & $0.030^{*}$ & 0.999 & 0.668 \\
\hline Cough & $175(70.0 \%)$ & $71(72.4 \%)$ & $110(77.5 \%)$ & 0.428 & 0.999 & 0.999 \\
\hline Fatigue or malaise & $107(42.8 \%)$ & $47(48.0 \%)$ & $78(54.9 \%)$ & 0.145 & 0.999 & 0.999 \\
\hline Rapid, shallow breathing & $25(10.0 \%)$ & $11(11.2 \%)$ & $14(9.9 \%)$ & 0.999 & 0.999 & 0.999 \\
\hline Gradual, unintended weight loss & 17 (6.8 \%) & 9 (9.2\%) & $24(16.9 \%)$ & $0.035^{*}$ & 0.317 & 0.999 \\
\hline Clubbing & $14(5.6 \%)$ & $11(11.2 \%)$ & $17(12.0 \%)$ & 0.309 & 0.999 & 0.321 \\
\hline Other & $1(0.4 \%)$ & 0 (0.0 \%) & $2(1.4 \%)$ & - & - & - \\
\hline GAP index, mean $(S D)^{c}$ & $3.3(1.5)$ & $3.5(1.5)$ & $3.7(1.4)$ & 0.149 & 0.999 & 0.774 \\
\hline \multicolumn{7}{|c|}{ Lung-function measures at IPF diagnosis, mean [median] (SD) } \\
\hline FVC (liters) & $2.6(1.1)$ & $2.4(0.9)$ & $2.4(1.0)$ & 0.821 & 0.999 & 0.796 \\
\hline FVC\% & $61.7 \%(26.1 \%)$ & $58.5 \%(24.0 \%)$ & $59.5 \%(27.6 \%)$ & 0.999 & 0.999 & 0.999 \\
\hline $\mathrm{FEV}_{1}$ (liters) & $2.0(0.9)$ & $1.8(0.7)$ & $1.7(0.6)$ & $0.021^{*}$ & 0.901 & 0.395 \\
\hline $\mathrm{FEV}_{1} / \mathrm{FVC}$ & $79.6 \%(12.6 \%)$ & $79.9 \%(11.8 \%)$ & $80.7 \%(12.5 \%)$ & 0.999 & 0.999 & 0.999 \\
\hline DLco percent predicted & $53.4 \%(14.4 \%)$ & $51.2 \%(16.1 \%)$ & $47.7 \%(16.5 \%)$ & $0.033^{*}$ & 0.583 & 0.962 \\
\hline
\end{tabular}

aLung-function change categories were defined as the relative change in FVC\% from index to approximately 6 months following IPF diagnosis. "Stable" was defined as decline $<5 \%$. "Marginal" was defined as decline $\geq 5 \%$ and $<10 \%$, while "Significant" was defined as decline $\geq 10 \%$

${ }^{b}$ Physicians were allowed to select multiple values for comorbidities and symptoms, so counts and percentages may not sum to the total $\mathrm{N}$ or $100 \%$

'Missing values for $\mathrm{DL}_{\text {co }}$ were imputed using a single imputation method in which observed $\mathrm{DL}_{\text {co }}$ was regressed on patient's index $\mathrm{FVC} \%$, age, gender, $\mathrm{BMI}$,

smoking status at diagnosis, exposure to environmental agents, comorbidities (including cardiac disorder, pulmonary hypertension, emphysema, and

gastroesophageal reflux disease), and symptoms at IPF diagnosis (including dyspnea/shortness of breath and gradual, unintended weight loss)

*All $p$-values were adjusted for multiple comparisons using the Bonferroni correction

FVC\% decline was associated with worse clinical outcomes and increased HRU during the subsequent period. In addition, experiencing a suspected AEx in the concurrent period was found to be a significant risk factor for mortality, hospitalization, and subsequent suspected AEx.

To our knowledge, this is one of the largest chart review studies conducted for IPF patients in the U.S. and the only one that attempts to link FVC\% change with HRU outcomes $[16,18,22]$. Results for clinical outcomes were similar to results from observational studies and randomized clinical trials [14, 16, 17, 23-26]. In particular, recent studies by Zappala et al. and Salisbury et al. have reported that patients with significant or marginal FVC declines were at higher risk of death compared to those with stable disease or not significant FVC decline
$[16,26]$. Results from the current study were reasonably concordant, especially for the comparison of the marginal FVC\% decline and stable groups. Results for AEx were also in line with prior studies. For instance, Kondoh et al. found a higher risk of subsequent AEx for patients with a significant FVC decline (i.e., $\geq 10 \%$ ) at 6 months compared to those without a significant decline, reporting a HR of 2.6 ( $p=0.049)$ [27]. The HR for our significant decline group relative to the stable group was similar at 2.86.

Beyond comparable findings, our study adds to the IPF literature by assessing the association of $\mathrm{FVC} \%$ change with HRU with a large cohort of IPF patients from a variety of practice settings. One recently published study reported that the proportion of hospitalization was $25 \%$ among patients with IPF and that $37 \%$ of hospitalizations resulted in an ICU stay [28]; our study reported 
Table 3 Clinical characteristics and healthcare resource utilization in the concurrent period by FVC\% change group

\begin{tabular}{|c|c|c|c|c|c|c|}
\hline & \multicolumn{6}{|c|}{ By lung-function change category (based on relative change in $\mathrm{FVC} \%)^{\mathrm{a}}$} \\
\hline & \multirow{2}{*}{$\begin{array}{l}\text { Stable }[A] \\
(N=250)\end{array}$} & \multirow{2}{*}{$\begin{array}{l}\text { Marginal [B] } \\
(N=98)\end{array}$} & \multirow{2}{*}{$\begin{array}{l}\text { Significant }[C] \\
(N=142)\end{array}$} & \multicolumn{3}{|c|}{ Relative effect measure $(95 \% \mathrm{Cl})$} \\
\hline & & & & {$[C]$ vs. $[A]$} & {$[C]$ vs. $[B]$} & {$[B]$ vs. $[A]$} \\
\hline & \multicolumn{3}{|c|}{ 6-Month IR per Patient } & \multicolumn{3}{|c|}{ IRR } \\
\hline \multirow[t]{2}{*}{ Rate of suspected AEX } & 0.21 & 0.25 & 0.25 & $1.20(0.69-2.09)$ & $1.00(0.55-1.82)$ & $1.20(0.63-2.28)$ \\
\hline & \multicolumn{3}{|c|}{ 6-Month Risk } & \multicolumn{3}{|c|}{ OR } \\
\hline Risk of suspected AEx & $14.1 \%$ & $16.7 \%$ & $20.4 \%$ & $1.56(0.78-3.15)$ & $1.27(0.56-2.91)$ & $1.23(0.56-2.70)$ \\
\hline \multirow[t]{2}{*}{ Risk of progression } & $23.4 \%$ & $38.7 \%$ & $48.6 \%$ & $3.09(1.67-5.72)$ & $1.50(0.75-3.00)$ & $2.07(1.07-3.97)$ \\
\hline & \multicolumn{3}{|c|}{ 6-Month IR per Patient } & \multicolumn{3}{|c|}{ IRR } \\
\hline Rate of IPF-related outpatient visits & 1.85 & 1.95 & 1.78 & $0.96(0.82-1.12)$ & $0.91(0.75-1.12)$ & $1.05(0.87-1.27)$ \\
\hline Unscheduled and/or urgent care & 0.16 & 0.23 & 0.22 & $1.42(0.64-3.15)$ & $0.97(0.48-1.96)$ & $1.46(0.76-2.80)$ \\
\hline For a suspected AEx & 0.17 & 0.19 & 0.19 & $1.16(0.58-2.31)$ & $1.04(0.52-2.09)$ & $1.11(0.54-2.29)$ \\
\hline Rate of IPF-related ER visits & 0.18 & 0.16 & 0.14 & $0.81(0.31-2.11)$ & $0.87(0.37-2.01)$ & $0.94(0.40-2.17)$ \\
\hline For a suspected AEx & 0.04 & 0.02 & 0.05 & $1.15(0.34-3.86)$ & $2.46(0.41-14.72)$ & $0.47(0.07-3.17)$ \\
\hline Rate of IPF-related hospitalizations & 0.06 & 0.08 & 0.05 & $0.80(0.20-3.12)$ & $0.59(0.17-1.98)$ & $1.36(0.35-5.20)$ \\
\hline For a suspected AEx & 0.04 & 0.06 & 0.04 & $0.96(0.19-4.82)$ & $0.63(0.17-2.32)$ & $1.52(0.27-8.60)$ \\
\hline Rate of hospital days & 0.39 & 0.48 & 0.25 & $0.63(0.10-3.82)$ & $0.52(0.10-2.62)$ & $1.22(0.28-5.26)$ \\
\hline Rate of ICU stays & 0.03 & 0.03 & 0.02 & $0.59(0.07-4.97)$ & $0.47(0.07-2.95)$ & $1.25(0.21-7.58)$ \\
\hline Rate of ICU days & 0.08 & 0.18 & 0.07 & $0.79(0.05-12.62)$ & $0.36(0.03-4.05)$ & $2.16(0.23-20.59)$ \\
\hline
\end{tabular}

AEx Acute exacerbation, IR incidence rate, IRR incidence rate ratio, OR odds ratio

aLung-function change categories were defined as the relative change in FVC\% from index to approximately 6 months following IPF diagnosis. "Stable" was defined as decline $<5 \%$. "Marginal" was defined as decline $\geq 5 \%$ and $<10 \%$, while "Significant" was defined as decline $\geq 10 \%$

12-month risks of $15 \%$ and $39 \%$ for these outcomes, respectively, and additionally links them to $\mathrm{FVC} \%$ decline. Comparison of our results to a claims study published in 2012 demonstrates that annual rates of outpatient visits and ER visits are similar, and the annual rate of hospitalization in our study is slightly lower $(0.53$ vs. 0.34) than the claims study [12]. Our lower rate of hospitalization is likely attributed to the fact that 1) the claims study reported all-cause hospitalizations, while our study focused on IPF-related hospitalizations; 2) we required patients to have a second FVC measurement approximately 6 months after

Table 4 Clinical outcomes in the subsequent period by FVC\% change group

\begin{tabular}{|c|c|c|c|c|c|c|}
\hline & \multicolumn{6}{|c|}{ By lung-function change category (based on relative change in FVC\%) ${ }^{\text {a }}$} \\
\hline & \multirow{2}{*}{$\begin{array}{l}\text { Stable }[A] \\
(N=250)\end{array}$} & \multirow{2}{*}{$\begin{array}{l}\text { Marginal }[B] \\
(N=98)\end{array}$} & \multirow{2}{*}{$\begin{array}{l}\text { Significant }[C] \\
(N=142)\end{array}$} & \multicolumn{3}{|c|}{ Relative effect measure $(95 \% \mathrm{Cl})$} \\
\hline & & & & [C] vs. $[\mathrm{A}]$ & {$[C]$ vs. $[B]$} & {$[\mathrm{B}]$ vs. $[\mathrm{A}]$} \\
\hline & \multicolumn{3}{|c|}{ 12-Month IR per Patient } & \multicolumn{3}{|c|}{ IRR } \\
\hline \multirow[t]{2}{*}{ Rate of suspected AEx } & 0.26 & 0.47 & 0.74 & $2.87(1.71-4.82)$ & $1.58(0.95-2.64)$ & $1.82(1.02-3.23)$ \\
\hline & \multicolumn{3}{|c|}{ 12-Month Risk } & \multicolumn{3}{|c|}{ OR } \\
\hline Risk of suspected AEx & $19.2 \%$ & $37.1 \%$ & $50.9 \%$ & $4.37(2.09-9.16)$ & $1.76(0.81-3.80)$ & $2.49(1.28-4.82)$ \\
\hline Risk of progression & $62.6 \%$ & $76.2 \%$ & $85.6 \%$ & $3.56(1.66-7.64)$ & $1.86(0.81-4.26)$ & $1.92(0.91-4.04)$ \\
\hline Mortality ${ }^{b}$ & \multicolumn{3}{|c|}{ Risk by 12 Months } & \multicolumn{3}{|c|}{$H R$} \\
\hline Death due to any cause & $6.4 \%$ & $13.1 \%$ & $28.0 \%$ & $5.05(2.75-9.27)$ & $1.85(1.05-3.26)$ & $2.73(1.51-4.94)$ \\
\hline Death due to IPF & $5.5 \%$ & $10.3 \%$ & $24.3 \%$ & $6.23(2.96-13.14)$ & $1.94(1.01-3.70)$ & $3.22(1.59-6.53)$ \\
\hline Death due to AEx & $5.0 \%$ & $9.3 \%$ & $13.1 \%$ & $3.91(1.56-9.84)$ & $1.22(0.54-2.77)$ & $3.21(1.41-7.30)$ \\
\hline
\end{tabular}

AEx acute exacerbation, $I R$ incidence rate, IRR incidence rate ratio, $O R$ odds ratio, $H R$ hazard ratio

a Lung-function change categories were defined as the relative change in FVC\% from index to approximately 6 months following IPF diagnosis. "Stable" was defined as decline $<5 \%$. "Marginal" was defined as decline $\geq 5 \%$ and $<10 \%$, while "Significant" was defined as decline $\geq 10 \%$

baplan-Meier survival analysis was used to estimate the risk of death by 12 months 
Table 5 Healthcare resource utilization outcomes in the subsequent period by FVC\% change group

\begin{tabular}{|c|c|c|c|c|c|c|}
\hline & \multicolumn{6}{|c|}{ By lung-function decline category (based on relative change in FVC\%) ${ }^{a}$} \\
\hline & \multirow{2}{*}{$\begin{array}{l}\text { Stable }[A] \\
(N=250)\end{array}$} & \multirow{2}{*}{$\begin{array}{l}\text { Marginal }[B] \\
(N=98)\end{array}$} & \multirow{2}{*}{$\begin{array}{l}\text { Significant }[C] \\
(N=142)\end{array}$} & \multicolumn{3}{|c|}{ Relative effect measure $(95 \% \mathrm{Cl}$ ) } \\
\hline & & & & [C] vs. $[\mathrm{A}]$ & [C] vs. [B] & {$[B]$ vs. $[A]$} \\
\hline & \multicolumn{3}{|c|}{ 12-Month IR per Patient } & \multicolumn{3}{|c|}{ IRR } \\
\hline Rate of IPF-related outpatient visits & 2.24 & 2.57 & 2.55 & $1.14(0.89-1.46)$ & $0.99(0.76-1.30)$ & $1.15(0.91-1.45)$ \\
\hline Unscheduled and/or urgent care & 0.18 & 0.38 & 0.54 & $3.01(1.51-5.97)$ & $1.41(0.78-2.55)$ & $2.13(1.05-4.34)$ \\
\hline For a suspected AEx & 0.19 & 0.33 & 0.54 & $2.81(1.47-5.40)$ & $1.64(0.86-3.11)$ & $1.72(0.80-3.69)$ \\
\hline \multicolumn{7}{|c|}{ Rate of outpatient visits indicating that the following medications/treatments were prescribed for IPF } \\
\hline Prednisone & 1.06 & 1.16 & 1.60 & $1.51(1.08-2.10)$ & $1.38(1.02-1.86)$ & $1.10(0.79-1.52)$ \\
\hline Azathioprine & 0.36 & 0.31 & 0.54 & $1.51(0.78-2.93)$ & $1.72(0.84-3.53)$ & $0.88(0.44-1.76)$ \\
\hline $\mathrm{N}$-acetylcysteine & 0.65 & 0.70 & 0.79 & $1.22(0.79-1.89)$ & $1.13(0.67-1.90)$ & $1.08(0.69-1.70)$ \\
\hline \multicolumn{7}{|c|}{ Rate of outpatient visits that included the following tests/procedures } \\
\hline Arterial blood gas test & 0.17 & 0.23 & 0.34 & $2.04(0.77-5.38)$ & $1.46(0.53-4.03)$ & $1.40(0.55-3.56)$ \\
\hline HRCT & 0.23 & 0.35 & 0.35 & $1.55(0.74-3.21)$ & $1.02(0.45-2.31)$ & $1.51(0.76-2.99)$ \\
\hline Chest X-ray & 0.48 & 0.66 & 0.60 & $1.23(0.75-2.02)$ & $0.90(0.55-1.48)$ & $1.36(0.84-2.20)$ \\
\hline Lung biopsy & 0.03 & 0.04 & 0.01 & $0.44(0.02-8.70)$ & $0.31(0.02-4.91)$ & $1.42(0.13-15.70)$ \\
\hline Pulmonary rehabilitation & 0.18 & 0.19 & 0.26 & $1.44(0.79-2.63)$ & $1.35(0.58-3.11)$ & $1.07(0.52-2.23)$ \\
\hline Rate of IFP-related ER visits & 0.35 & 0.54 & 0.53 & $1.53(0.71-3.28)$ & $0.98(0.51-1.87)$ & $1.56(0.66-3.71)$ \\
\hline For a suspected AEx & 0.13 & 0.22 & 0.29 & $2.22(0.95-5.21)$ & $1.32(0.60-2.87)$ & $1.69(0.67-4.27)$ \\
\hline \multicolumn{7}{|c|}{ Rate of ER visits that included the following tests/procedures } \\
\hline Arterial blood gas test & 0.15 & 0.35 & 0.33 & $2.24(1.01-4.99)$ & $0.95(0.45-2.00)$ & $2.36(1.01-5.49)$ \\
\hline HRCT & 0.09 & 0.18 & 0.20 & $2.17(0.85-5.58)$ & $1.09(0.37-3.22)$ & $1.99(0.60-6.67)$ \\
\hline Chest X-ray & 0.20 & 0.28 & 0.30 & $1.51(0.69-3.32)$ & $1.10(0.55-2.21)$ & $1.37(0.61-3.09)$ \\
\hline Supplemental oxygen therapy & 0.17 & 0.23 & 0.29 & $1.74(0.73-4.14)$ & $1.26(0.52-3.04)$ & $1.39(0.46-4.20)$ \\
\hline Rate of IPF-related hospitalizations & 0.24 & 0.32 & 0.61 & $2.53(0.70-9.10)$ & $1.89(0.94-3.78)$ & $1.34(0.34-5.29)$ \\
\hline For a suspected AEx & 0.09 & 0.21 & 0.43 & $4.69(1.84-11.99)$ & $2.05(1.03-4.08)$ & $2.29(0.82-6.35)$ \\
\hline Rate of hospital days & 1.13 & 2.32 & 5.25 & $4.63(1.31-16.42)$ & $2.27(0.86-5.97)$ & $2.05(0.66-6.33)$ \\
\hline Rate of ICU stays & 0.05 & 0.17 & 0.26 & $4.95(1.20-20.41)$ & $1.53(0.59-3.99)$ & $3.23(0.72-14.53)$ \\
\hline Rate of ICU days & 0.30 & 0.69 & 1.22 & $4.05(0.79-20.91)$ & $1.75(0.58-5.35)$ & $2.31(0.54-9.83)$ \\
\hline \multicolumn{7}{|c|}{ Rate of hospitalizations that included the following tests/procedures } \\
\hline Arterial blood gas test & 0.10 & 0.19 & 0.35 & $3.58(1.33-9.64)$ & $1.87(0.73-4.80)$ & $1.92(0.61-6.00)$ \\
\hline Mechanical ventilation & 0.04 & 0.11 & 0.14 & $3.29(0.63-17.23)$ & $1.33(0.38-4.70)$ & $2.47(0.57-10.73)$ \\
\hline Non-invasive ventilation & 0.02 & 0.08 & 0.22 & $10.17(3.25-31.86)$ & $2.80(1.05-7.51)$ & $3.63(0.90-14.70)$ \\
\hline \multirow[t]{2}{*}{ Supplemental oxygen therapy } & 0.07 & 0.13 & 0.28 & $3.95(1.38-11.29)$ & $2.11(0.93-4.82)$ & $1.87(0.62-5.66)$ \\
\hline & \multicolumn{3}{|c|}{ 12-Month Risk } & \multicolumn{3}{|c|}{ OR } \\
\hline Risk of having $\geq 1$ outpatient visit & $97.5 \%$ & $97.3 \%$ & $95.0 \%$ & $0.48(0.14-1.62)$ & $0.52(0.12-2.20)$ & $0.93(0.23-3.76)$ \\
\hline Unscheduled or urgent care & $11.4 \%$ & $26.9 \%$ & $34.5 \%$ & $4.10(1.95-8.63)$ & $1.43(0.69-2.98)$ & $2.87(1.39-5.92)$ \\
\hline For a suspected AEx & $12.7 \%$ & $21.9 \%$ & $33.8 \%$ & $3.52(1.62-7.67)$ & $1.82(0.82-4.05)$ & $1.93(0.90-4.15)$ \\
\hline Risk of having $\geq 1$ ER visit & $14.4 \%$ & $29.4 \%$ & $32.4 \%$ & $2.85(1.36-5.98)$ & $1.15(0.53-2.52)$ & $2.47(1.22-5.03)$ \\
\hline For a suspected AEx & $7.8 \%$ & $16.7 \%$ & $22.1 \%$ & $3.33(1.40-7.94)$ & $1.42(0.57-3.54)$ & $2.35(0.98-5.65)$ \\
\hline Risk of having $\geq 1$ hospitalizations & $7.8 \%$ & $19.1 \%$ & $30.0 \%$ & $5.04(2.13-11.93)$ & $1.82(0.71-4.66)$ & $2.76(1.14-6.70)$ \\
\hline Intensive care unit (ICU) stay & $2.4 \%$ & $8.4 \%$ & $12.4 \%$ & $5.86(1.43-24.01)$ & $1.56(0.41-5.90)$ & $3.77(0.88-16.03)$ \\
\hline For a suspected AEx & $5.9 \%$ & $15.1 \%$ & $27.8 \%$ & $6.08(2.45-15.07)$ & $2.16(0.84-5.54)$ & $2.81(1.10-7.20)$ \\
\hline
\end{tabular}

IR incidence rate, IRR incidence rate ratio, $O R$ odds ratio

aLung-function change categories were defined as the relative change in FVC\% from index to approximately 6 months following IPF diagnosis. "Stable" was defined as decline $<5 \%$. "Marginal" was defined as decline $\geq 5 \%$ and $<10 \%$, while "Significant" was defined as decline $\geq 10 \%$ 
Table 6 Multivariable Cox proportional hazards regression on mortality in the subsequent period

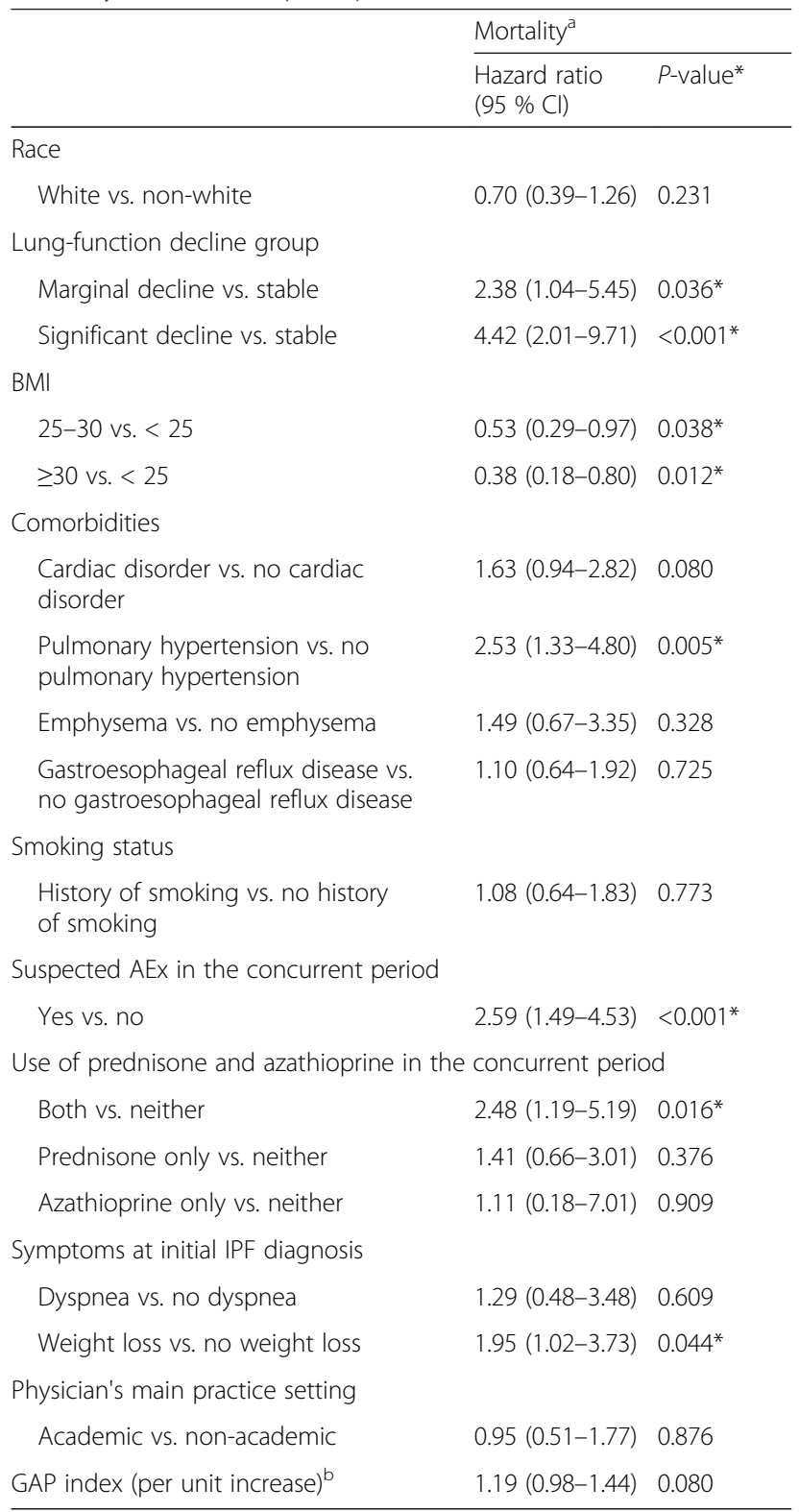

${ }^{a}$ Multivariable Cox proportional hazard regression was used to estimate the hazard ratio, $95 \%$ confidence interval and p-value, accounting for physician clustering using generalized estimating equations

${ }^{\mathrm{b}}$ The hazard ratio for the GAP index was estimated for every one point increase in GAP index

*P-values less than 0.05 are indicated with an asterisk (*)

diagnosis. Requiring a second FVC measurement may have excluded the most severe of patients who may have been hospitalized and died early in their disease course.

In addition to evaluating the relationship between FVC\% change and outcomes, our multivariable models provide information on patient characteristics associated with mortality, hospitalization, and AEx, adding to the literature on risk factors for these outcomes. AEx in the concurrent period was a consistent and strong risk factor across all these outcomes and was the strongest predictor of a subsequent AEx. Combination therapy with prednisone and azathioprine was associated with a significantly higher mortality risk relative to use of neither drug with an HR of $2.48(p=0.016)$, which is consistent with the findings of the PANTHER-IPF trial [21].

Select comorbidities were also significant predictors of worse outcomes as determined through our multivariable Cox regression models. In particular, pulmonary hypertension was a strong risk factor of all three adverse outcomes. While our result for mortality is concordant with the findings of numerous other studies, there is only a single prior report attesting to a relationship between pulmonary hypertension and AEx [29-32]. Furthermore, our finding of non-Caucasian patients being associated with worse outcomes adds to the literature on the disparities in health outcomes among IPF patients.

\section{Strengths and limitations}

Our study has several strengths. The study population came from different treating settings, including patients treated in the community, which is likely more reflective of real-world practice in IPF. A large number of patient charts were contributed by pulmonologists from a national physician panel, allowing for a broad sample of IPF patients across the U.S. Patient charts provided more comprehensive individual patient details and clinical granularity, which are not commonly collected in administrative claims data. Thus, our data source helps to better understand and capture underlying risk factors and allowed us to adjust for important observed confounders in the multivariable regression models. IPF diagnosis was confirmed by HRCT or biopsy as reported by the pulmonologist and is likely to be more accurate than a claims-based IPF patient identification algorithm.

This study is subject to the limitations of retrospective studies. To account for temporal trends in IPF care and management, we sampled patients who were recently diagnosed with IPF. Consequently, the findings may not be applicable to patients diagnosed with IPF prior to 2011. Also, there is the potential for incomplete patient chart information and data entry errors from participating pulmonologists. To address these possible limitations, patient inclusion criteria required pulmonologist access to the patient's complete inpatient and outpatient medical records related to IPF post-diagnosis. Real-time data checks for consistency and logic of responses were included in the online case report form to reduce the likelihood of data entry errors, such as ensuring that the dates of specific IPF-related events collected in the follow-up period were after the initial IPF diagnosis date.

Our study did not further stratify patients who had smaller declines or improvement in FVC\% within the 
Table 7 Multivariable Cox proportional hazards regression on hospitalization in the subsequent period

\begin{tabular}{|c|c|c|}
\hline & \multicolumn{2}{|l|}{ Hospitalization $^{a}$} \\
\hline & $\begin{array}{l}\text { Hazard Ratio } \\
(95 \% \mathrm{Cl})\end{array}$ & $P$-value* \\
\hline \multicolumn{3}{|l|}{ Race } \\
\hline White vs. non-white & $0.50(0.32-0.79)$ & $0.003^{*}$ \\
\hline \multicolumn{3}{|l|}{ Lung-function decline group } \\
\hline Marginal decline vs. stable & $2.50(1.06-5.91)$ & $0.033^{*}$ \\
\hline Significant decline vs. stable & $3.37(1.62-7.00)$ & $<0.001^{*}$ \\
\hline \multicolumn{3}{|l|}{ BMl } \\
\hline $25-30$ vs. $<25$ & $0.59(0.34-1.03)$ & 0.061 \\
\hline$\geq 30$ vs. $<25$ & $0.95(0.51-1.74)$ & 0.861 \\
\hline \multicolumn{3}{|l|}{ Comorbidities } \\
\hline $\begin{array}{l}\text { Cardiac disorder vs. no cardiac } \\
\text { disorder }\end{array}$ & $1.87(1.06-3.32)$ & $0.032^{*}$ \\
\hline $\begin{array}{l}\text { Pulmonary hypertension } \\
\text { vs. no pulmonary hypertension }\end{array}$ & $2.09(1.15-3.83)$ & $0.017^{*}$ \\
\hline Emphysema vs. no emphysema & $1.44(0.62-3.36)$ & 0.399 \\
\hline $\begin{array}{l}\text { Gastroesophageal reflux disease } \\
\text { vs. no gastroesophageal reflux disease }\end{array}$ & $1.08(0.67-1.73)$ & 0.746 \\
\hline \multicolumn{3}{|l|}{ Smoking status } \\
\hline $\begin{array}{l}\text { History of smoking vs. no history } \\
\text { of smoking }\end{array}$ & $1.02(0.61-1.70)$ & 0.935 \\
\hline \multicolumn{3}{|l|}{ Suspected AEx in the concurrent period } \\
\hline Yes vs. no & $1.86(1.06-3.26)$ & $0.030^{*}$ \\
\hline \multicolumn{3}{|c|}{ Use of prednisone and azathioprine in the concurrent period } \\
\hline Both vs. neither & $1.24(0.59-2.62)$ & 0.575 \\
\hline Prednisone only vs. neither & $1.25(0.72-2.16)$ & 0.428 \\
\hline Azathioprine only vs. neither & $0.74(0.09-6.38)$ & 0.780 \\
\hline \multicolumn{3}{|l|}{ Symptoms at initial IPF diagnosis } \\
\hline Dyspnea vs. no dyspnea & $1.43(0.43-4.80)$ & 0.562 \\
\hline Weight loss vs. no weight loss & $1.45(0.77-2.76)$ & 0.250 \\
\hline \multicolumn{3}{|l|}{ Physician's main practice setting } \\
\hline Academic vs. non-academic & $0.89(0.51-1.55)$ & 0.680 \\
\hline GAP index (per unit increase) ${ }^{b}$ & $1.23(1.04-1.46)$ & $0.018^{*}$ \\
\hline
\end{tabular}

${ }^{a}$ Multivariable Cox proportional hazard regression was used to estimate the hazard ratio, $95 \%$ confidence interval and $p$-value, accounting for physician clustering using generalized estimating equations

${ }^{\mathrm{b}}$ The hazard ratio for the GAP index was estimated for every one point increase in GAP index

*P-values less than 0.05 are indicated with an asterisk $(*)$

stable group. Even though this group was classified as being stable, patients in this group had reasonably high risk of progression (62.6\%), suspected AEx (19.2\%), and all-cause mortality (6.4\%) over 12 months (Table 4). They also utilized a significant amount of resources in the subsequent period. Future studies teasing out the impact of smaller declines in $\mathrm{FVC} \%$, perhaps in
Table 8 Multivariable Cox proportional hazards regression on suspected acute exacerbation in the subsequent period

\begin{tabular}{|c|c|c|}
\hline & \multicolumn{2}{|l|}{$\begin{array}{l}\text { Suspected Acute } \\
\text { Exacerbation }^{\mathrm{a}}\end{array}$} \\
\hline & $\begin{array}{l}\text { Hazard Ratio } \\
(95 \% \mathrm{Cl})\end{array}$ & $P$-value* \\
\hline \multicolumn{3}{|l|}{ Race } \\
\hline White vs. non-white & $0.63(0.45-0.88)$ & $0.007^{*}$ \\
\hline \multicolumn{3}{|l|}{ Lung-function decline group } \\
\hline Marginal decline vs. stable & $2.02(1.13-3.59)$ & $0.011^{*}$ \\
\hline Significant decline vs. stable & $2.86(1.69-4.85)$ & $<0.001^{*}$ \\
\hline \multicolumn{3}{|l|}{ BMl } \\
\hline $25-30$ vs. $<25$ & $0.82(0.53-1.26)$ & 0.362 \\
\hline$\geq 30$ vs. $<25$ & $0.75(0.45-1.23)$ & 0.245 \\
\hline \multicolumn{3}{|l|}{ Comorbidities } \\
\hline $\begin{array}{l}\text { Cardiac disorder vs. no cardiac } \\
\text { disorder }\end{array}$ & $1.57(1.04-2.37)$ & $0.031^{*}$ \\
\hline $\begin{array}{l}\text { Pulmonary hypertension } \\
\text { vs. no pulmonary hypertension }\end{array}$ & $1.65(1.03-2.63)$ & $0.036^{*}$ \\
\hline Emphysema vs. no emphysema & $1.89(1.02-3.50)$ & $0.043^{*}$ \\
\hline $\begin{array}{l}\text { Gastroesophageal reflux disease } \\
\text { vs. no gastroesophageal reflux disease }\end{array}$ & $1.07(0.74-1.54)$ & 0.736 \\
\hline \multicolumn{3}{|l|}{ Smoking status } \\
\hline $\begin{array}{l}\text { History of smoking vs. no history } \\
\text { of smoking }\end{array}$ & $0.91(0.64-1.31)$ & 0.608 \\
\hline \multicolumn{3}{|l|}{ Suspected AEx in the concurrent period } \\
\hline Yes vs. no & $2.98(1.92-4.62)$ & $<0.001^{*}$ \\
\hline \multicolumn{3}{|c|}{ Use of prednisone and azathioprine in the concurrent period } \\
\hline Both vs. neither & $1.40(0.76-2.55)$ & 0.276 \\
\hline Prednisone only vs. neither & $1.23(0.81-1.87)$ & 0.335 \\
\hline Azathioprine only vs. neither & $0.99(0.32-3.05)$ & 0.980 \\
\hline \multicolumn{3}{|l|}{ Symptoms at initial IPF diagnosis } \\
\hline Dyspnea vs. no dyspnea & $1.39(0.68-2.83)$ & 0.368 \\
\hline Weight loss vs. no weight loss & $1.16(0.66-2.05)$ & 0.595 \\
\hline \multicolumn{3}{|l|}{ Physician's main practice setting } \\
\hline Academic vs. non-academic & $1.02(0.69-1.51)$ & 0.910 \\
\hline GAP index (per unit increase) ${ }^{b}$ & $1.07(0.94-1.22)$ & 0.301 \\
\hline
\end{tabular}

${ }^{a}$ Multivariable Cox proportional hazard regression was used to estimate the hazard ratio, $95 \%$ confidence interval and p-value, accounting for physician clustering using generalized estimating equations

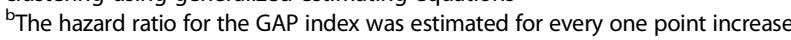
in GAP index

${ }^{*} P$-values less than 0.05 are indicated with an asterisk $(*)$

conjunction with other measures of progression, may provide insight.

The pulmonologist-reported suspected AEx in this study is another limitation, because the determination likely does not reflect the definition established by Collard et al. in 2007 [3]. More specifically, pulmonologists may use less stringent criteria in their practice settings 
when classifying AEx due to their patients' inability to undergo certain procedures required by the definition. Consequently, the rate of suspected AEx observed in this study may be higher than the rate of AEx reported in clinical trials $[5,33]$. We speculate that some cases of increased respiratory compromise for other reasons may have been erroneously labeled as a suspected AEx, a term that has indeed been recently defined in the literature [34]. On the other hand, our study provides insight into how AEx are perceived and defined in real-world clinical practice. As demonstrated in our study, these events still have profound implications on downstream HRU even if based on less strict criteria.

Lastly, our study might not have included patients on both ends of the disease spectrum. Specifically, requiring that eligible patients have two FVC measures may have excluded patients with more severe disease who were unable to perform lung-function tests or those who did not survive long enough to receive the subsequent FVC assessment. On the other end of the spectrum, there might have been some milder, more stable patients who were not seen or did not have lung-function testing within the timeline specified in this study.

\section{Conclusions}

In summary, our study demonstrates that greater $\mathrm{FVC} \%$ decline in the first 6 months after the initial IPF diagnosis is associated with worse clinical outcome and increased IPF-related HRU. The incremental burden of FVC\% decline on patients and the healthcare system may underscore the importance of preservation of lung function in IPF patients. Future studies examining treatments that help slow lung function deterioration are warranted along with additional studies identifying predictors of patients at greatest risk of $\mathrm{FVC} \%$ decline in the months following diagnosis and evaluating variation in effect of lung-function change across subgroups of patients. Our study further highlights the need for definitions and categorization of IPF worsening events that are more applicable to IPF physicians' daily practice and capture less severe events than those defined by the Collard definition. Finally, management options that ameliorate declines in FVC may have an impact on and help to improve health outcomes in patients with IPF.

\section{Appendix}

\section{Explanation of imputation for missing value in $\mathrm{DL}_{\mathrm{co}}$}

Missing values for $\mathrm{DL}_{\mathrm{CO}}$ were imputed using a single imputation method based on a linear regression in which observed $\mathrm{DL}_{\mathrm{CO}}$ was regressed on patient's index $\mathrm{FVC \%}$, age, gender, BMI, smoking status at diagnosis, exposure to environmental agents, comorbidities (including cardiac disorder, pulmonary hypertension, emphysema, and gastroesophageal reflux disease), and symptoms at IPF diagnosis (including dyspnea/shortness of breath and gradual, unintended weight loss).

\section{Table 9 Physician characteristics}

\begin{tabular}{l} 
Physicians $(N=168)$ \\
\hline $\mathrm{N}(\%)$ or $\quad$ Median \\
Mean (SD)
\end{tabular}

Practice characteristics

$\begin{array}{ll}\text { Main practice setting, N (\%) } & \\ \text { Academic } & 69(41.1 \%) \\ \text { Non-academic } & 99(58.9 \%) \\ \text { Practice location, N (\%) } & \\ \text { Northeast } & 61(36.3 \%) \\ \text { South } & 42(25.0 \%) \\ \text { Midwest } & 35(20.8 \%) \\ \text { West } & 30(17.9 \%)\end{array}$

Physician characteristics

Years in pulmonology practice, $\quad 15.0(6.4) \quad 14 \quad[3,30]$ mean (SD) median [min, max]

Percentage of time spent in inpatient vs. outpatient settings, mean (SD) median [min, max]
Inpatient settings

Outpatient settings

Participation in IPF-related research

during the past year, $\mathrm{N}(\%)^{\mathrm{a}, \mathrm{b}}$

IPF clinical trial involvement

Other IPF research involvement

None

$39.0(17.2) \quad 40 \quad[5,90]$

$61.0(17.2) \quad 60 \quad[10,95]$

$20(11.9 \%)$

$13(7.7 \%)$

$138(82.1 \%)$
Physician-reported profile of treated

patients (January 1, 2011 - June 20, 2013)

Number of patients diagnosed with interstitial lung disease (ILD), mean

$132.7(182.4) \quad 60$

$[4,1000]$

(SD) median [min, max]

\begin{tabular}{|c|c|c|c|}
\hline $\begin{array}{l}\text { Number of ILD patients diagnosed } \\
\text { with IPF }\end{array}$ & $76.2(93.5)$ & 45 & {$[3,600]$} \\
\hline $\begin{array}{l}\text { Number of deaths within } \\
6 \text { months of IPF diagnosis }\end{array}$ & $10.0(17.4)$ & 5 & {$[0,150]$} \\
\hline $\begin{array}{l}\text { Number of deaths within } \\
12 \text { months of IPF diagnosis }\end{array}$ & $20.6(38.7)$ & 8 & {$[0,350]$} \\
\hline $\begin{array}{l}\text { Percent of ILD patients diagnosed } \\
\text { with IPF }\end{array}$ & $68.4(26.3)$ & 72 & {$[8,100]$} \\
\hline $\begin{array}{l}\text { Percent of IPF patients dying } \\
\text { within } 6 \text { months of IPF diagnosis }\end{array}$ & $12.3(11.4)$ & 10 & {$[0,60]$} \\
\hline $\begin{array}{l}\text { Percent of IPF patients dying } \\
\text { within } 12 \text { months of IPF diagnosis }\end{array}$ & $26.0(22.6)$ & 20 & {$[0,94]$} \\
\hline acted $^{c}$, mean & $2.9(1.2)$ & 3 & {$[1,4]$} \\
\hline
\end{tabular}

(SD) median [min, max]

${ }^{a}$ Research involvement includes IPF-related basic clinical research, epidemiology studies, outcomes studies, etc.

${ }^{b}$ Physicians were allowed to select multiple values for type of research involvement, so counts and percentages may not sum to the total $\mathrm{N}$ or $100 \%$ ${ }^{c}$ Physicians have been permitted to abstract a maximum of 4 patient charts 
Table 10 Healthcare resource utilization outcomes in the subsequent period

\begin{tabular}{lllll}
\hline & \multicolumn{4}{l}{ By lung-function change category (based on relative change in FVC\%) } \\
\cline { 2 - 5 } & All Patients & Stable or Marginal & Significant & Relative Effect Measure \\
& & $(\Delta<10 \%)[\mathrm{A}]$ & $(\Delta \geq 10 \%)[\mathrm{B}]$ & $(95 \% \mathrm{Cl})$ \\
& $(N=490)$ & $(N=348)$ & $(N=142)$ & {$[\mathrm{B}]$ vs. [A] } \\
\hline
\end{tabular}

Subsequent Period

12-Month IR per Patient

Rate of IPF-related outpatient visits

2.39

0.30

0.30

For a suspected AEX

Rate of outpatient visits indicating that the following medications/treatments were prescribed for IPF

$\begin{array}{llll}\text { Prednisone } & 1.22 & 1.09 & 1.60 \\ \text { Azathioprine } & 0.39 & 0.34 & 0.54 \\ \text { N-acetylcysteine } & 0.70 & 0.67 & 0.79\end{array}$

$\begin{array}{ll}2.34 & 2.56 \\ 0.24 & 0.55 \\ 0.24 & 0.54\end{array}$

IRR

$1.09(0.91-1.32)$

$2.25(1.45-3.50)$

$2.28(1.47-3.51)$

$1.19(0.85-1.67)$
$1.47(1.16-1.85)$

$1.57(0.96-2.57)$

$1.80(0.90-3.60)$

$1.32(0.75-2.33)$

$1.11(0.77-1.59)$

$0.39(0.05-3.44)$

$1.40(0.86-2.27)$

$1.30(0.80-2.12)$

$1.84(1.04-3.27)$

$1.63(0.95-2.81)$

$1.71(0.88-3.30)$

$1.36(0.79-2.32)$

$1.58(0.89-2.79)$

$2.31(1.10-4.85)$

$3.46(2.00-5.98)$

$1.84(0.38-9.07)$

4.19 (1.69-10.41)

3.07 (1.38-6.83)

$2.92(1.12-7.63)$

$2.87(1.48-5.54)$

$2.47(0.85-7.12)$

$5.50(2.90-10.45)$

$3.22(1.69-6.17)$

Supplemental oxygen therapy

0.13

0.07

0.36

0.16

0.20

0.28

$I R$ Incidence rate, $I R R$ Incidence rate ratio

aLung-function change categories were defined as the relative change in FVC\% from index to approximately 6 months following IPF diagnosis. "Stable or Marginal" was defined as decline less than $10 \%$, while "Significant" was defined as decline greater than or equal to $10 \%$

\section{Abbreviations}

AEx: Acute exacerbation; ALAT: Latin American Thoracic Association; ATS: American Thoracic Society; BMI: Body mass index; Cl: Confidence interval; $\mathrm{DL}_{\mathrm{co}}$ : Single breath diffusing capacity for the lung for carbon monoxide; ER: Emergency room; ERS: European Respiratory Society; $\mathrm{FEV}_{1}$ : Forced expiratory volume after $1 \mathrm{~min}$; FVC: Forced vital capacity; FVC\%: FVC percent predicted; GAP index: Gender-age-physiology index; GEE: Generalized estimating equations; HR: Hazard ratio; HRCT: High-resolution computed tomography; HRU: Healthcare resource utilization; ICU: Intensive care unit; IPF: Idiopathic pulmonary fibrosis; IR: Incidence rate; IRR: Incidence rate ratio; JRS: Japanese Respiratory Society; OR: Odds ratio; SD: Standard deviation.

\section{Competing interests}

WMR, DSM, and EQW are employees of Analysis Group, Inc., which received funding from Boehringer Ingelheim Pharmaceuticals, Inc. (BIPI) to conduct this study. SDN is a consultant for BIPI, Celgene, Genetech, Gilead, and Intermune. He has also received research funding from Actelion, BIPI, Fibrogen, 
Intermune, Sanofi-Aventis and Veracyte for IPF studies. YFY is an employee of BIPI. This study was funded by BIPI.

\section{Authors' contributions}

WMR and DSM contributed to the study design, data acquisition, statistical analysis, and drafted the manuscript. EQW and YFY contributed to the study design and conception, interpretation of the data, and critically revised the manuscript. SDN contributed to the interpretation of the data and critically revised the manuscript. All authors read and approved the final manuscript.

\section{Acknowledgements}

Contribution towards medical writing and analytical support was provided by Todor Totev of Analysis Group, Inc.

\section{Author details}

${ }^{1}$ Analysis Group, Inc., Boston, MA, USA. ${ }^{2}$ Boehringer Ingelheim Pharmaceuticals, Inc., Ridgefield, CT, USA. ${ }^{3}$ Analysis Group, Inc., New York, NY, USA. ${ }^{4}$ Advanced Lung Disease and Transplant Program, Department of Medicine, Inova Fairfax Hospital, Falls Church, VA, USA.

Received: 14 July 2015 Accepted: 14 December 2015

Published online: 29 December 2015

\section{References}

1. Raghu G, Weycker D, Edelsberg J, Bradford WZ, Oster G. Incidence and prevalence of idiopathic pulmonary fibrosis. Am J Respir Crit Care Med. 2006;174:810-6.

2. Raghu G, Chen S-Y, Yeh W-S, Maroni B, Li Q, Lee Y-C, et al. Idiopathic pulmonary fibrosis in Medicare beneficiaries: incidence, prevalence and survival. A41 Interstitial Lung Dis. Risk Factors Outcomes [Internet]. American Thoracic Society; 2014. A1514-A1514. [cited 2015 Feb 24]. Available from: http://www.atsjournals.org/doi/abs/10.1164/ajrccm-conference.2014.189.1 MeetingAbstracts.A1514.

3. Collard HR, Moore BB, Flaherty KR, Brown KK, Kaner RJ, King TE, et al. Acute Exacerbations of Idiopathic Pulmonary Fibrosis. Am J Respir Crit Care Med. 2007:176:636-43

4. Nathan SD, Shlobin OA, Weir N, Ahmad S, Kaldjob JM, Battle E, et al. Longterm course and prognosis of idiopathic pulmonary fibrosis in the new millennium. Chest. 2011;140:221-9.

5. Raghu G, Collard HR, Egan JJ, Martinez FJ, Behr J, Brown KK, et al. An official ATS/ERS/JRS/ALAT statement: idiopathic pulmonary fibrosis: evidence-based guidelines for diagnosis and management. Am J Respir Crit Care Med. 2011; 183:788-824.

6. Pulmonary Fibrosis Foundation. Treatment [Internet]. Treat. PFF. [cited 2015 Jan 15]. Available from: http://www.pulmonaryfibrosis.org/life-with-pf/ pulmonary-fibrosis-treatment-options.

7. U.S. Food and Drug Administration (FDA). FDA approves Ofev to treat idiopathic pulmonary fibrosis [Internet]. 2014 [cited 2015 Jun 30]. Available from: http://www.fda.gov/NewsEvents/Newsroom/PressAnnouncements/ ucm418994.htm.

8. U.S. Food and Drug Administration (FDA). FDA approves Esbriet to treat idiopathic pulmonary fibrosis [Internet]. 2014 [cited 2015 Jun 30]. Available from: http://www.fda.gov/newsevents/newsroom/pressannouncements/ ucm418991.htm.

9. Raghu G, Rochwerg B, Zhang Y, Garcia CAC, Azuma A, Behr J, et al. An official ATS/ERS/JRS/ALAT clinical practice guideline: treatment of idiopathic pulmonary fibrosis. An update of the 2011 clinical practice guideline. Am J Respir Crit Care Med. 2015:192:e3-19.

10. Swigris JJ, Kuschner WG, Jacobs SS, Wilson SR, Gould MK. Health-related quality of life in patients with idiopathic pulmonary fibrosis: a systematic review. Thorax. 2005;60:588-94.

11. De Vries J, Kessels BL, Drent M. Quality of life of idiopathic pulmonary fibrosis patients. Eur Respir J. 2001;17:954-61.

12. Collard HR, Ward AJ, Lanes S, Cortney Hayflinger D, Rosenberg DM, Hunsche E. Burden of illness in idiopathic pulmonary fibrosis. J Med Econ. 2012;15:829-35.

13. Wu N, Yu YF, Chuang C-C, Wang R, Benjamin NN, Coultas DB. Healthcare resource utilization among patients diagnosed with idiopathic pulmonary fibrosis in the United States. J Med Econ. 2015;18:249-57.

14. du Bois RM, Weycker D, Albera C, Bradford WZ, Costabel U, Kartashov A, et al. Forced vital capacity in patients with idiopathic pulmonary fibrosis: test properties and minimal clinically important difference. Am J Respir Crit Care Med. 2011;184:1382-9.

15. Martinez FJ, Safrin S, Weycker D, Starko KM, Bradford WZ, King J, et al. The clinical course of patients with idiopathic pulmonary fibrosis. Ann Intern Med. 2005;142:963-7.

16. Zappala CJ, Latsi PI, Nicholson AG, Colby TV, Cramer D, Renzoni EA, et al. Marginal decline in forced vital capacity is associated with a poor outcome in idiopathic pulmonary fibrosis. Eur Respir J. 2010;35:830-6.

17. Collard HR, King TE, Bartelson BB, Vourlekis JS, Schwarz MI, Brown KK. Changes in clinical and physiologic variables predict survival in idiopathic pulmonary fibrosis. Am J Respir Crit Care Med. 2003;168:538-42.

18. Jegal Y, Kim DS, Shim TS, Lim C-M, Do Lee S, Koh Y, et al. Physiology is a stronger predictor of survival than pathology in fibrotic interstitial pneumonia. Am J Respir Crit Care Med. 2005;171:639-44.

19. American Medical Association (AMA). AMA master list of pulmonologists. 2013.

20. Ley B, Ryerson CJ, Vittinghoff E, Ryu JH, Tomassetti S, Lee JS, et al. A multidimensional index and staging system for idiopathic pulmonary fibrosis. Ann Intern Med. 2012;156:684-91.

21. The Idiopathic Pulmonary Fibrosis Clinical Research Network. Prednisone, azathioprine, and $N$-acetylcysteine for pulmonary fibrosis. N. Engl. J. Med. 2012; 366:1968-77.

22. Naqvi SB, Kim HJ, Tomic R, Bhargava M, Perlman D. Acute exacerbation of idiopathic pulmonary fibrosis following lung biopsy: a case series. A41 Interstitial Lung Dis. Risk Factors Outcomes [Internet]. American Thoracic Society; 2014. A6585-A6585. [cited 2015 Mar 16]. Available from: http:// www.atsjournals.org/doi/abs/10.1164/ajrccm-conference.2014.189.1 MeetingAbstracts.A6585.

23. Flaherty KR, Mumford JA, Murray S, Kazerooni EA, Gross BH, Colby TV, et al. Prognostic implications of physiologic and radiographic changes in idiopathic interstitial pneumonia. Am J Respir Crit Care Med. 2003;168:543-8.

24. King TE, Safrin S, Starko KM, Brown KK, Noble PW, Raghu G, et al. Analyses of efficacy end points in a controlled trial of interferon-gamma1b for idiopathic pulmonary fibrosis. Chest. 2005:127:171-7.

25. Taniguchi $H$, Kondoh $Y$, Ebina M, Azuma A, Ogura T, Taguchi Y, et al. The clinical significance of $5 \%$ change in vital capacity in patients with idiopathic pulmonary fibrosis: extended analysis of the pirfenidone trial. Respir Res. 2011:12:93.

26. Salisbury ML, Xia M, Zhou Y, Murray S, Tayob N, Brown KK, et al. Idiopathic Pulmonary Fibrosis: Gender-Age-Physiology Index Stage for Predicting Future Lung Function Decline. Chest. 2015.

27. Kondoh Y, Taniguchi H, Katsuta T, Kataoka K, Kimura T, Nishiyama O, et al. Risk factors of acute exacerbation of idiopathic pulmonary fibrosis. Sarcoidosis Vasc Diffuse Lung Dis Off J WASOG World Assoc Sarcoidosis Granulomatous Disord. 2010:27:103-10.

28. Brown AW, Fischer CP, Shlobin OA, Buhr RG, Ahmad S, Weir NA, et al. Outcomes after hospitalization in idiopathic pulmonary fibrosis: a cohort study. Chest. 2015;147:173-9.

29. Lettieri CJ, Nathan SD, Barnett SD, Ahmad S, Shorr AF. Prevalence and outcomes of pulmonary arterial hypertension in advanced idiopathic pulmonary fibrosis. Chest. 2006:129:746-52.

30. Whelan TPM, Dunitz JM, Kelly RF, Edwards LB, Herrington CS, Hertz MI, et al. Effect of preoperative pulmonary artery pressure on early survival after lung transplantation for idiopathic pulmonary fibrosis. J Heart Lung Transplant Off Publ Int Soc Heart Transplant. 2005;24:1269-74

31. Nadrous HF, Pellikka PA, Krowka MJ, Swanson KL, Chaowalit N, Decker PA, et al. Pulmonary hypertension in patients with idiopathic pulmonary fibrosis. Chest. 2005:128:2393-9.

32. Judge EP, Fabre A, Adamali HI, Egan JJ. Acute exacerbations and pulmonary hypertension in advanced idiopathic pulmonary fibrosis. Eur Respir J. 2012; 40:93-100.

33. Richeldi L, du Bois RM, Raghu G, Azuma A, Brown KK, Costabel U, et al. Efficacy and safety of nintedanib in idiopathic pulmonary fibrosis. N Engl J Med. 2014;370:2071-82

34. Collard HR, Yow E, Richeldi L, Anstrom KJ, Glazer C, IPFnet investigators. Suspected acute exacerbation of idiopathic pulmonary fibrosis as an outcome measure in clinical trials. Respir Res. 2013:14:73. 